\title{
Delivering Bad News: Aspects to Consider When Training Medical Students and Residents
}

\author{
1Jose Leonardo Loaiza, ${ }^{2}$ Ana Maria Arroyave \\ ${ }^{1}$ Assistant Professor, Department of Family and Community Medicine, Paul L Foster School of Medicine, Texas Tech University \\ Health Sciences Center, 9849 Kenworthy, El Paso, Texas 79924, USA \\ ${ }^{2}$ Assistant Professor of Medical Education, Clinical Assistant Professor of Family and Community Medicine, Paul L Foster \\ School of Medicine, Texas Tech University Health Sciences Center, 5001 El Paso Drive, El Paso, Texas 79905, USA
}

Correspondence: Jose Leonardo Loaiza, Assistant Professor, Department of Family and Community Medicine, Paul L Foster School of Medicine, Texas Tech University Health Sciences Center, 9849 Kenworthy, El Paso, Texas 79924, USA Phone: (915) 7573178 Ext. 274, Fax: (915) 7514378, e-mail: leonardo.loaiza@ttuhsc.edu

\begin{abstract}
Ultrasound advances have made a tremendous impact in the field of obstetrics and gynecology. The routinely use of this technology has allowed doctors to diagnose medical conditions in real time. When ultrasound reveals a serious diagnosis or a finding of concern (i.e. fetal demise, fetal malformation, a suspicious mass), communicating bad news to the patient and family represents a challenge that most doctors don't feel comfortable doing. In the following section we will present a clinical vignette, that involves a fetus with multiple structural malformations diagnosed by ultrasound, to show some general principles that can help physicians to break bad news. We also highlight the importance of incorporating formal training in medical school to help students become familiar and more comfortable delivering bad news.
\end{abstract}

Keywords: Ultrasound, bad news, deliver, ultrasound, communication.

\section{INTRODUCTION}

Most medical professionals feel some degree of apprehension when they are about to engage in a conversation with a patient about an unexpected outcome. Despite experience in their fields, the truth is that they never received training in the art of delivering bad news either in medical school or residency. ${ }^{1,2}$

The rapid advance of ultrasound technology in the medical field has allowed physicians to use this resource more and more. One of the medical fields where ultrasound has had a tremendous impact is in gynecology and obstetrics. In the 60's and 70's most of the congenital abnormalities were diagnosed at the time of birth. ${ }^{3}$ The frustration, the sense of failure and acute grief were then addressed by the pediatrician. Nowadays during pregnancy, ultrasound is available and expected at all levels of prenatal care. Ultrasound is a powerful tool to perform prenatal diagnosis and anticipate outcomes. This technology has created an increasing number of unprecedented prenatal diagnoses that challenge the need to train physicians to deliver news to their patients.

Most doctors believe that the words used when delivering bad news is the most important part of the message. Patients usually recall vividly how the message was delivered and more precisely the physician's manner and style. ${ }^{1,4}$ It is unfortunate that we spend many hours learning the symptoms, signs, diagnostic tools and treatments in several medical illnesses and conditions and very little learning communication skills.

The first code of medical ethics by the American Medical Association in 1847 stated, "The life of a sick person can be shortened not only by the acts, but also by the words or the manner of a physician. It is, therefore, a sacred duty to guard himself carefully in this respect, and to avoid all things which have a tendency to discourage the patient and to depress his spirits."

Delivering bad news inappropriately can be distressing for both giver and recipient. To the recipient, the patient, bad news causes great stress and can lead to psychological morbidity. ${ }^{5,6}$ The effects can be long-lasting. For the physician giving a patient bad news, implies a challenge in patient-physician relationship. ${ }^{7}$

\section{CASE REPORT}

Priscilla is a Hispanic 29 years old female with a pregnancy of 18 weeks. She came to see her primary doctor because she had some vaginal blood spotting during the weekend 
that resolved spontaneously. She is a G2P0, who had a miscarriage 18 months ago. She also has diabetes and hypertension that have been managed with insulin and oral meds. The miscarriage caused tremendous stress since she was trying to get pregnant for the last 3 years. Priscilla, has been following your medical advice and after the DM and HTN were controlled she was very excited to be pregnant again. She has been seeing a local Obs and Gyne who ordered an ultrasound 2 weeks ago, but Pricilla was waiting for her husband to be in town to have it done. Priscilla seems to be doing fine now, except for a very mild vaginal discharge with some blood tinge. You advised her to get the ultrasound today.

\section{BAD NEWS: WHAT IS IT?}

Bad news has been defined as any information that is subjectively appraised by patients or their loved ones as negatively affecting their view of their future. ${ }^{8}$ The impact of such information cannot be judged without knowledge of what a patient already knows and expects. Stereotypically, bad news is almost always associated with a terminal diagnosis; however, primary care doctors encounter many situations that involve reporting bad news. For example: the new happy pregnant woman who goes to the first ultrasound with her husband and family to find out the unfortunate fact that the baby has no heart beat; or that the baby has major fetal structural abnormalities.

It's hard: let's face it. Nobody likes to be the bearer of bad news. Physicians are not the exception, since we don't wish to take hope away. We are fearful of dealing with a family's reaction to the news and we don't want to think that we failed the patient. On the other hand, most of us have not received formal training in how to deal with difficult questions, and with angry and frustrated patients that may blame the doctor for the message. Several studies have shown that the way a physician communicates can affect patient satisfaction, ${ }^{8,9}$ adherence to treatment ${ }^{9}$ and quality of life. ${ }^{1}$ When communication is poor, studies have shown that it is related with physician burnout and increased litigation. ${ }^{4,10,12}$

How to do it? There are several articles in the medical literature that have addressed this issue. All of them have in common the following: prepare, ensure that the patient is properly informed and has understood the message, and acknowledge the patient's immediate needs after the interview. Several articles suggest the use of a "systematic approach" as it facilitates a "check out" list so all the steps involved in the process are followed. We suggest the list proposed by Doctor Geoffrey H. Gordon ${ }^{7}$ with a few modifications by citing other authors that we find useful.

\section{PREPARATION}

Familiarize yourself with the relevant clinical information. Make sure that the labs, X-rays, actually belong to your patient! Be prepared to tell basic information about the course of the illness, prognosis and therapeutic approaches. $8,11,14$ During the work-up, if you strongly think about a terminal illness (metastasized cancer) or a catastrophic outcome (fetal demise), prepare the patient for that possibility. Take this opportunity to ask the patient how he or she would like to receive the news.

Doctor: "Priscilla, although many women can have vaginal spotting during pregnancy, we need to make sure that everything is OK. I think we should get that ultrasound today; in that way we will be able to plan the best way to go. As soon as I get the ultrasound result I will let you know. Would you like me to call you? Or you would like to come?"

\section{SETTING}

Arrange for a time and place with minimum interruptions. Turn off your cell phone, pager and other noisy devices. Mentally rehearse how you will deliver the news, you may want to script what phrases to use or avoid. Use simple understandable terms. Prepare emotionally. Always take responsibility for delivering bad news in person. Introduce yourself to everyone present and ask for relationship with the patient. Determine the patient's preferences for what and how much they want to know and whether or not they want a relative with them. Sit down at eye level and give them your full attention and concern. ${ }^{12,13}$

You learned that the fetal ultrasound revealed multiple congenital anomalies consistent with triploidy. You called Priscilla and when she asked you about the result you reply: "The ultrasound is abnormal. I would like to explain it carefully. Would you like to have someone present with you when I go over this?"

\section{DELIVERING THE NEWS}

Make sure that you take the patient through the process that led to the work-up. This will allow the patient to understand that several steps have been taken before you 
give the diagnosis. At this point, many patients have already consulted several sources to know their possibilities and therapeutic options (i.e., friends, internet, books, other patients). ${ }^{7}$ They have already developed an "illness model" that is important to elicit since you will be able to identify and clarify misconceptions that the patient has formed. ${ }^{13}$

Doctor: Priscilla, I sent you to have this ultrasound done because I wanted to see how the baby was doing. "I have the results now."

Now, give a "warning shot" 15 and then a small amount of information in simple words. Speak frankly but compassionately. Avoid humor or flippant comments. ${ }^{16}$

Doctor: "I am sorry, but I have bad news. I am afraid that this is more serious than I thought..... Unfortunately the baby has several malformations".

Some doctors prefer a different technique that is based on the fact that some patients remember very little about what was told after the bad news was given. ${ }^{7,16}$

Doctor: "Whatever I tell you in a moment, I want you to remember that I am here to help you. The situation is serious, but there is plenty we can do. I am sorry, but your baby has several malformations."

In order to relieve their own anxiety, physicians have the tendency to lecture about the details, using scientific language when the patient is actually digesting one line ("my baby is not normal" or "my baby is dead"). At this time silence is your friend; especially if emotions set in. Take this time to respond to the patient's feelings by acknowledging and validating them.

Doctor: "I know how terrible this is for you. I want you to know that I will continue to be your doctor and work with you on this."

\section{EMOTIONAL SUPPORT}

Getting bad news is primarily emotional that's why some patients react with fear, grief, shock, or even aggressiveness. It is challenging for the provider to remain present with patients having strong emotional reactions. ${ }^{7}$ There are no magic words to say. Sit near the patient and use empathic statements. Avoid arguing or criticizing colleagues. Avoid defensiveness regarding your or a colleague's medical care. ${ }^{4}$ It is important to point to the angry patient that it is the medical condition, not the doctor, the enemy and that doctor and patient must work together to fight it.
Patient: "Why the other doctor told me that everything was fine!!"

Or: "I told you that I did not want insulin therapy, but you insisted!"

Doctor: "I know how hard this is for you. I understand how you feel. You may have some questions about this later and I will be available to talk."

Some young practitioners find it very intimidating to think that an angry patient won't listen and will sue them. Frustration and anger that patients and relatives express should lead the provider to actively listen to identify any misinterpretations. This can often provide a wonderful opportunity to address the foundation of their anger. ${ }^{17}$

Be aware of cultural differences. Some patients will appreciate being held by their hand or shoulder. If the patient is alone ask if there is anyone who should be called.

\section{OFFER A REALISTIC HOPE}

Even if a cure is not realistic or outcomes cannot be changed, offer hope and encouragement about what options are available. Some providers actually use this approach before giving the news.

To physicians, hope and reassurance bring in mind cure, pain relief, prolonged survival and immediate recuperation. To the patient hope can mean reconciliation with friends, gathering with family, or the opportunity to try it again (as in our patient's case).

Patient: "It's been so hard to get pregnant, and now this."

Doctor: "I know, but I want you to realize that you have been able to control your diabetes and hypertension, and this has been progress in your well-being that will help us to ....".

Doctor: "I can only imagine how painful this is for you, but we need to start planning about what to do next."

Double checking: At this point it is important to check if your message was well-understood. You may take this time to assess the relative's thoughts and how they understood the news.

Doctor: "Priscilla, before we talk about the options and future plans, it is very important for me to know what is your understanding of what I just explained to you."

\section{CLOSING THE INTERVIEW}

The majority of patients will be willing to know what to do next and what to expect. This is another opportunity to 
reassure them that you will be with them and help to get other team members that will participate in their future care. This interaction with other members of the team (genetic counselors, social workers, and mental health clinicians) will reassure and inform the patient about what happened and will help her to understand and to accept the news.

With the increased number of prenatal diagnosis of major fetal abnormalities, patients are forced to make decisions regarding management. At this point it is paramount that you are familiar with all the options and scenarios possible. Even the less "logical" option, may be the most attractive to a patient. Whatever they choose is their right. Our obligation is to present the options in simple words, in the less biased way.

Patient: "What's next?"

Doctor: "As you already learned, the baby's condition is severe. Chances for him to make it until the end of pregnancy are slim." What do you want to do, Priscilla?"

\section{DOES TRAINING HELP TO DELIVER BAD NEWS?}

As we stated before, medical education in both pregraduate and postgraduate levels lack proper training to develop the skills to communicate well. Different approaches can be incorporated during medical school and residency to develop such skills. In fact some studies using cancer survivors in role-playing exercises with medical students have shown how the students learned preferred communication techniques and gained confidence with the task of "breaking bad news". Using feedback from cancer survivors during these encounters they are able to learn and follow a format that will help them to understand the importance of having a systematic approach while giving bad news. ${ }^{18}$ Other studies have incorporated a standardized format to deliver bad news that is evaluated during the OSCE training. The same class was divided in two large groups. One of them received formal training in delivering bad news. The results showed that the students who took the training had more confidence during the encounter and the feedback received by the standardized patient was superior.

Some of our patients that have had a fetal demise have told us about how fast the ultrasound went. They were not sure if such a rapid test could tell whether the baby is dead. Some wonder if the machine was working properly. Taking the time to scan a fetus, offering to show the screen and explain what is there will prevent uncertainty. These are tasks not formally taught in ultrasound training. Ultrasound technology has redefined obstetrics; the physician rapport with his/her patient will never be displaced as the cornerstone of medical care. ${ }^{17}$

\section{REFERENCES}

1. Orlander J, Fincke B, Hermanns D, Johnson G. Medical residents' first clearly remembered experiences of giving bad news. J Gen Intern Med 2002;17:825-40.

2. Baile W, Lanzi R, Parker P, et al. Oncologists' attitudes toward and practices in giving bad news: An exploratory study. J Clin Oncol 2002;20:2189-96.

3. Woods J, Strategies for communicating bad news in obstetrics, http://www.perifacts.com/pdf/Bad_news_DISCLOSURE.pdf.: Rochester.

4. Beckman H, Markakis K, Suchman A, Frankel R. The doctorpatient relationship and malpractice: Lessons from plaintiff deposicion 1994;2002;154:1365-70.

5. Gunderman R. Patient communication: What to teach to radiology residents. AJR Am J Roentgenol 2001;177:41-43.

6. Sickles E, Philpotts L, Parkinson B, et al. American college of Radiology/Society of Breast Imaging curriculum for resident and fellow education in breast imaging. J Am Coll Radiol 2006;3:279884.

7. Gordon G, Giving Bad News, in: Christensen J, Feldman M Ed. Behavioral Medicine in Primary Care. McGraw Hill Companies 2003;17-22.

8. Buckman R, Breaking bad news: Why is it still so difficult. $\mathrm{Br}$ Med J 1984;288:1597-99.

9. Ptacek J, Eberhardt T, Breaking Bad News: A review of the literature. JAMA 1996;276:496-502.

10. Berlin L, Communicating findings of radiologic examinations: whither goest the radiologist's duty? AJR Am J Roentgenol 2002;179:809-15.

11. Armstrong L, It's not about the bike: My journey back to life. New York: Putnam 2000.

12. Roberts C, Cox C, Reintgen D, Baile W, Gibertini M. Influence of physician communication on newly diagnosed breast patients' psychologic adjustment and decision-making. Cancer 1994;74:336-41.

13. Woods J. Loss During Pregnancy or in the Newborn Period (Ed). Woods J, Philadelphia: Jannetti Publishers 1997.

14. Kaplan S, Greenfield S, Ware J. Assessing the effects of physician-patient interactions on the outcomes of chronic disease. Med Care 1989;27(suppl):S110-27.

15. Baile W, Buckam R, Lenzi R, Glober G, Beale E, Kudelka A, Spikes: A six step protocol for delivering bad news: Application to the patient with cancer. Oncologist 2000;5:302-11.

16. VandeKieft G, Breaking bad news. American Family Physician 2001;64(12):1975-78.

17. Woods J, Rosovsky F. What Do I say and How Do I Say? Communicating Intended and Unintended Events In Obstetrics. 1993 San Francisco: Jossy Bass.

18. Liebert MI. Breaking bad news: Use of cancer survivors in roleplaying exercises. Journal of Palliative medicine 2008;11(6). 